Arq. Bras. Med. Vet. Zootec., v.67, n.5, p.1399-1407, 2015

\title{
Aspectos qualitativos e produção de biomassa em pastos de aveia e azevém cultivados puros ou consorciados e submetidos a pastejo leniente
}

\author{
[Qualitative aspects and biomass production in oats and ryegrass pastures cultivated pure or \\ intercropping and subjected to lenient grazing] \\ G.C. Guzatti, P.G. Duchini, A.F. Sbrissia, H.M.N. Ribeiro-Filho* \\ Universidade do Estado de Santa Catarina - UDESC - Lages, SC
}

\begin{abstract}
RESUMO
Pastos consorciados de aveia e azevém anual têm sido recomendados para uso no inverno/primavera em ambientes subtropicais. No entanto, o impacto do pastejo leniente sobre parâmetros qualitativos e produtivos destes, comparativamente aos seus monocultivos, é pouco conhecido. Objetivou-se avaliar possíveis variações nas composições morfológica e bromatológica, além da produção de biomassa em pastos de aveia-preta (Avena strigosa cv. IAPAR 61) e azevém anual (Lolium multiflorum Lam. cv. comum) quando cultivados puros ou em consórcio ao longo de toda estação de crescimento e submetidos a pastejo leniente. Os três tratamentos (aveia pura, azevém puro e aveia + azevém em consórcio) foram distribuídos em um delineamento em blocos completos ao acaso, com quatro repetições. Novilhas da raça Holandesa foram utilizadas como agentes de desfolhação, e os pastos foram rebaixados em $40 \%$ da altura inicial quando as alturas atingiam 17,20 e $23 \mathrm{~cm}$ para o azevém, o consórcio e a aveia, respectivamente. A relação lâmina:colmo diminuiu com o avanço da estação de crescimento em todos os tratamentos, mas a proporção de colmos no estrato pastejável se manteve abaixo de $20 \%$ da matéria seca até o início do estádio de desenvolvimento reprodutivo, independentemente do tipo de pasto. Os teores de proteína bruta e fibra em detergente neutro no estrato pastejável foram, respectivamente, superiores a $16 \%$ e inferiores a $50 \%$ nos quatro primeiros ciclos de pastejo. O consórcio e o azevém puro apresentaram as maiores taxas de acúmulo médio de forragem $\left(32,6 \mathrm{~kg} \mathrm{MS} \mathrm{ha}{ }^{-1} \mathrm{dia}^{-1}\right)$, porém o maior período de utilização do consórcio resultou em maior produção total de matéria seca $\left(4809 \mathrm{~kg} \mathrm{MS} \mathrm{ha}^{-1}\right)$. O pastejo leniente não prejudica a qualidade da forragem no estrato pastejável durante todo o estádio de desenvolvimento vegetativo de pastos anuais de inverno. A associação entre aveia-preta e azevém anual aumenta a produção de matéria seca total de forragem em comparação aos mesmos pastos cultivados puros.
\end{abstract}

Palavras-chave: Avena strigosa Schreb., Lolium multiflorum Lam., relação lâmina colmo, taxa de acúmulo

\begin{abstract}
Mixed pastures of oats + annual ryegrass have been considered a good alternative for animal feeding during the winter/spring period in subtropical regions. However, the impacts of lenient grazing under their qualitative and productive aspects, when compared to their monoculture, remain unclear. Thus, the aim of this study was to evaluate the morphological and chemical composition and biomass production of black oat (Avena strigosa cv. IAPAR 61) and annual ryegrass (Lolium multiflorum Lam cv. common) swards cultivated pure or intercropped, throughout the growing season and submitted to lenient grazing. Treatments (oats, annual ryegrass and intercropping oats + annual ryegrass) were arranged in a complete randomized block design with four replications. The pastures were defoliated in $40 \%$ of pregrazing height by Holstein heifers, when the heights reached 17, 20 and $23 \mathrm{~cm}$ for the ryegrass, intercrop and oat, respectively. The leaf blade:stem ratio decreased with the advance of the growing season for all treatments, but the proportion of stems in the grazed stratum remained lower than $20 \%$ of dry matter
\end{abstract}

Recebido em 31 de outubro de 2014

Aceito em 8 de maio de 2015

*Autor para correspondência (corresponding author)

E-mail: henrique.ribeiro@udesc.br 


\section{Guzatti et al.}

until the pastures begun reproductive development. Similarly, the crude protein (CP) and neutral detergent fiber (NDF) levels in grazed stratum were, respectively, above $16 \%$ and below $50 \%$ from the first to fourth grazing cycles. Mixed pastures of black oat + ryegrass and ryegrass alone had higher forage accumulation rate (average $=32.6 \mathrm{~kg} \mathrm{DM} \mathrm{ha}^{-1}$ day $^{-1}$ ), but mixed pastures were used for a longer period, resulting in a greatest total DM production $\left(4809 \mathrm{~kg} \mathrm{DM} \mathrm{h}^{-1}\right)$. Lenient grazing does not reduce the forage quality in potential grazing layer throughout the growing vegetative stage. Intercropping black oat and ryegrass increases total DM production when compared to their monocultures.

Keywords: Avena strigosa Schreb, Lolium multiflorum Lam, leaf stem/ratio, accumulation rate

\section{INTRODUÇÃO}

A região Sul do Brasil apresenta baixas temperaturas de maio a setembro, o que limita a produção de forragem das pastagens nativas e naturalizadas por serem formadas principalmente por espécies estivais (Soares et al., 2005). Nesse cenário, os produtores necessitam de alternativas para contornar o déficit forrageiro nessa época do ano, sendo o uso de pastagens cultivadas hibernais uma opção viável para manter elevados índices zootécnicos (Moreira et al., 2005; Hellbrugg et al., 2008). Entre as espécies mais utilizadas de acordo com o levantamento realizado pelo Sebrae/Senar/Farsul (2005), estão a aveia-preta (Avena strigosa) e o azevém anual (Lolium multiflorum Lam.). Segundo esse relatório, $81 \%$ dos produtores do Rio Grande do Sul utilizam pastagem anual cultivada de inverno, sendo que desse total, $56 \%$ implantam aveia e azevém em consórcio. A associação tem por objetivo aproveitar as diferentes sazonalidades de produção dessas espécies, sendo a aveia responsável pela produção de outono-inverno e o azevém de inverno-primavera (Carvalho et al., 2010).

Destaca-se, contudo, que a obtenção de elevada produção por animal e por área depende, entre outros fatores, do manejo apropriado do pasto, o qual pode ser conduzido em função de critérios como altura ou oferta de forragem. Nesse sentido, quando os pastos são manejados sob lotação intermitente, observam-se reduções no consumo diário de forragem e no desempenho animal quando os pastos são rebaixados além de $40 \%$ da altura pré-pastejo.(Fonseca et al., 2012). Todavia, o uso de pastejo leniente pode resultar em aumento da proporção de colmos no dossel ao longo da estação de crescimento dos pastos (Miguel et al., 2012). Além disso, segundo Carrère et al. (2006), o consórcio entre gramíneas pode apresentar qualidade bromatológica reduzida em comparação ao monocultivo das espécies utilizadas na mistura. Esses resultados seriam decorrentes do incremento no tamanho das estruturas de sustentação das plantas, reflexo direto da competição por luz no interior do relvado. Entretanto, ainda é pouco conhecido o impacto do pastejo leniente sobre as características estruturais e a composição químicobromatológica de pastos de aveia e azevém em consórcio, em comparação aos cultivos puros.

Da mesma forma, o efeito da utilização da aveia e do azevém em cultivo puro ou consorciado sobre a produtividade primária dos pastos ainda é susceptível a interpretações duvidosas devido à diferença na sazonalidade produtiva dessas espécies. Isto porque estudos com ecossistemas pastoris constituídos por espécies nativas têm sugerido que as diferenças de flutuação populacional (Allan et al., 2011) bem como das características estruturais (Spehn et al., 2000) em ambientes multiespecíficos podem aumentar a produtividade primária desses sistemas ao longo do ano. De forma contrária, a maior precocidade e o maior tamanho da aveia poderiam dificultar o desenvolvimento do azevém e prejudicar a produtividade primária do consórcio na segunda metade do período de utilização dessa pastagem, quando a espécie mais tardia se tornaria mais importante no acúmulo de forragem (Harris e Thomas, 1972).

Assim, objetivou-se: (1) testar se o pastejo leniente de pastos de aveia-preta e azevém anual, puros ou em consórcio, reduz a quantidade de folhas e prejudica a composição químicobromatológica da forragem no estrato pastejável ao longo do período de utilização; e (2) avaliar se o uso dessas espécies em consórcio é capaz de resultar em taxas de acúmulo e produção total de matéria seca superiores aos cultivos puros. 


\section{MATERIAL E MÉTODOS}

$\mathrm{O}$ trabalho foi conduzido no município de Lages, SC ( $27^{\circ} 47^{\prime}$ S e $50^{\circ} 18^{\prime}$ O), de 27 de junho a 6 de novembro de 2011. O solo da área experimental é classificado como cambissolo húmico alumínico léptico, argiloso, com horizonte A moderado (Embrapa, 2006). As adubações foram realizadas em função da análise do solo, levando em consideração o cultivo anterior de milheto (Pennisetum glaucum), de acordo com o Manual de Adubação e Calagem para Santa Catarina e Rio Grande do Sul, Brasil (Comissão de química e fertilidade do solo - RS/SC, 2004) (ver Duchini et al., 2014). Durante o ano experimental, não houve restrição hídrica e as temperaturas mínimas, médias e máximas registradas se situaram próximas às médias hitóricas (Fig. 1).

Os pastos foram implantados em 12 parcelas de $98 \mathrm{~m}^{2}$ cada, semeadas com azevém anual (Lolium multiflorum Lam. cv. Comum; cultivar de ciclo curto), aveia-preta (Avena strigosa cv. IAPAR61; cultivar de ciclo longo e tardio) ou o consórcio dessas espécies. A semeadura foi realizada no dia 20 de abril de 2011, com cultivo mínimo do solo, e a densidade de semeadura foi de $50 \mathrm{~kg} / \mathrm{ha}$ para o azevém, $100 \mathrm{~kg} / \mathrm{ha}$ para a aveia e $120 \mathrm{~kg} / \mathrm{ha}$ para o consórcio, na proporção de 3:1 (90kg de aveia e $30 \mathrm{~kg}$ de azevém). Foram utilizadas quantidades de sementes acima das recomendadas (recomendação segundo Santos et al., 2009 - densidade de semeadura entre 50-95, 20-30 e 70-90kg/ha para a aveia, o azevém e o consórcio, respectivamente), a fim de permitir um rápido estabelecimento e máximo estande de plantas nas áreas, visto que, após o estabelecimento das pastagens, o autodesbaste de perfilhos regula a população de plantas de acordo com o manejo do pastejo utilizado (HernándezGarayet al., 1999).

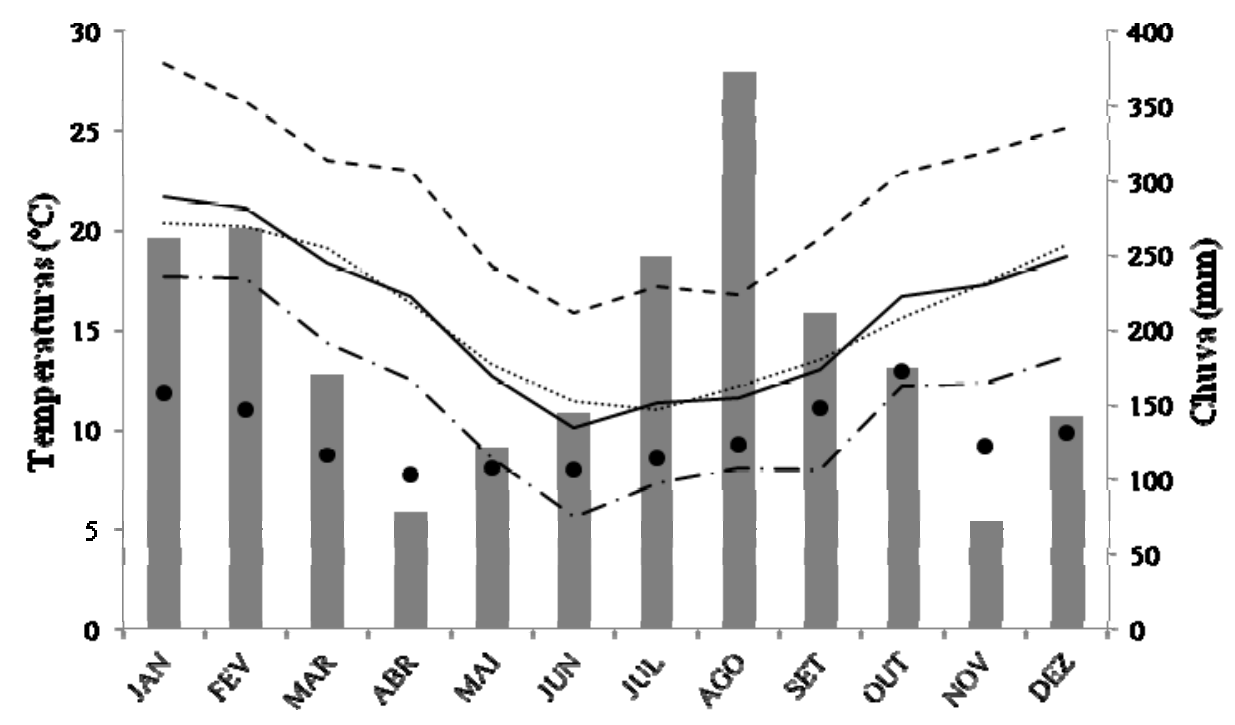

Figura 1. Condições climáticas do ano experimental e as médias históricas para a cidade de Lages - SC. Chuva média do ano (-); chuva média histórica $(\bullet)$; temperatura mínima do ano ( $\left.\because-{ }^{-}\right)$; temperatura máxima do ano (----); temperatura média do ano (-); temperatura média histórica (…).

Os três tratamentos experimentais consistiram de aveia-preta em cultivo puro, azevém anual em cultivo puro e aveia-preta + azevém anual em consórcio. $\mathrm{O}$ delineamento experimental utilizado foi em blocos completos ao acaso, com quatro repetições (parcelas). Os pastos foram manejados sob lotação intermitente, sendo rebaixados em $40 \%$ da altura estabelecida para pré-pastejo por três novilhas da raça Holandesa, manejo esse que não limita a taxa de ingestão de bovinos em pastejo (Fonseca et al., 2012). O azevém puro era desfolhado quando atingia a altura de $17 \mathrm{~cm}$, devido ao elevado alongamento de colmos a partir de $18 \mathrm{~cm}$ (Santos et al., 2015). Considerando que a aveia é uma planta de porte mais alto, quando cultivada pura, era desfolhada 
com $23 \mathrm{~cm}$, e o consórcio, para não favorecer uma ou outra espécie, em uma altura intermediária de $20 \mathrm{~cm}$. As alturas pré e póspastejo de cada parcela foram medidas em 50 pontos com auxílio de um bastão graduado (sward stick).

A biomassa aérea em pré e pós-pastejo foi quantificada pela relação entre a altura comprimida, medida com prato ascendente (Farmworks ${ }^{\circledR}, \quad$ F200, New Zealand), e a quantidade de MS presente na área do prato $\left(0,1 \mathrm{~m}^{2}\right)$. Para isso, em cada ciclo de pastejo foram coletadas oito amostras em pré e oito amostras em pós-pastejo para cada tipo de pasto (duas por parcela). As amostras foram coletadas desde os locais com menor quantidade aparente de biomassa aérea até os locais com maior quantidade. A biomassa aérea presente em cada um desses oito pontos foi cortada em nível do solo e seca em estufa com ventilação forçada de ar a $65^{\circ} \mathrm{C}$ até peso constante. De posse desses dados, foram geradas equações de regressão para a estimativa da biomassa aérea $\left(\mathrm{kg} \mathrm{MS} \mathrm{ha}^{-1}\right)$ pré e pós-pastejo de cada tipo de pasto em função da altura comprimida média $(\mathrm{cm}$ de unidade de disco) em cada parcela. A altura comprimida média de cada parcela foi calculada mediante 30 leituras tomadas com o prato ascendente. A taxa de acúmulo de forragem ( $\mathrm{kg}$ de MS. $\left.\mathrm{ha}^{-1} \mathrm{dia}^{-1}\right)$ foi calculada pela diferença entre a biomassa aérea pré-pastejo de um ciclo e a biomassa aérea póspastejo do ciclo anterior.

A fim de determinar a composição químicobromatológica e a relação lâmina:colmo dos pastos, foram coletadas, antes de cada pastejo, 20 subamostras por parcela, em nível do solo, para compor uma amostra com aproximadamente $700 \mathrm{~g}$ de forragem fresca. Essas amostras foram homogeneizadas e divididas em duas subamostras, sendo uma utilizada para determinação da composição químicobromatológica (apenas da fração acima da altura residual) e outra para composição morfológica (todo o dossel). As alturas residuais de cada parcela foram determinadas pela altura média de perfilho estendido, após cada pastejo, obtida por meio de 50 leituras tomadas com uma régua graduada em milímetros.

Para realização das análises químicobromatológicas, as amostras foram secas em estufa com ventilação forçada, a $65^{\circ} \mathrm{C}$, durante
72 horas. Posteriormente, foram moídas em peneira de $1 \mathrm{~mm}$, e determinaram-se os teores de matéria seca (MS), proteína bruta (PB), fibra em detergente neutro (FDN) e fibra em detergente ácido (FDA). Os teores de $\mathrm{MS}$ foram determinados por secagem em estufa a $105^{\circ} \mathrm{C}$ por, no mínimo, 12 horas. $\mathrm{O}$ nitrogênio $(\mathrm{N})$ total foi estimado pelo método de Kjedhal, e os teores de $\mathrm{PB}$ foram calculados multiplicando-se os teores de $\mathrm{N}$ por 6,25. Para determinação dos teores de FDN e FDA, foi utilizada a técnica sequencial proposta por Van Soest et al. (1991), adaptada para o aparelho Fiber analyser (ANKOM Technology, Macedon NY, USA).

Os dados referentes ao número de ciclos de pastejo e o somatório da biomassa de forragem produzida pelos diferentes tipos de pasto foram submetidos à análise de variância considerandose o efeito de bloco e tratamento (Procedimento GLM, SAS ${ }^{\circledR}$, versão 9.2). A taxa média de acúmulo de forragem foi analisada utilizando-se o procedimento MIXED (modelos mistos) do pacote estatístico $\mathrm{SAS}^{\circledR}$. Nesse caso, o ciclo de pastejo foi considerado como medida repetida no tempo, levando-se em conta efeito fixo de tratamento e bloco, efeito aleatório de ciclo de pastejo e da interação tratamento $\times$ ciclo de pastejo.

O efeito do ciclo de pastejo sobre as composições químico-bromatológica e morfológica dos pastos foi avaliado por análise de regressão. Para cada variável, os coeficientes de regressão angular dos diferentes tratamentos foram comparados por um teste " $\mathrm{t}$ ". Quando identificada a similaridade entre tratamentos, uma única equação foi gerada para avaliar a influência dos ciclos sobre essas variáveis. A estimativa das médias foi realizada por meio do LSMEANS, e a diferença entre elas pela probabilidade de diferença (PDIFF), utilizandose o teste " $\mathrm{t}$ " de Student a 5\% de significância.

\section{RESULTADOS}

Os teores de MS, FDN e FDA da forragem aumentaram e os de $\mathrm{PB}$ diminuíram linearmente $(\mathrm{P}<0,001)$ com o avanço da estação de crescimento dos pastos (Fig. 2). No mesmo sentido, a relação lâmina:colmo na biomassa aérea reduziu-se exponencialmente $(\mathrm{P}<0,001)$ desde o primeiro ciclo de pastejo (Fig. 3a), mas a proporção de colmo + peseudocolmo acima do 
resíduo se manteve abaixo de $20 \%$ da MS total até o quarto ciclo de pastejo, aumentando exponencialmente $(\mathrm{P}<0,001)$ no quinto e sexto ciclos (Fig. 3b).

O primeiro ciclo de pastejo foi realizado em datas semelhantes nos diferentes tipos de pasto, porém o azevém apresentou o último pastejo 15 dias antes dos demais tratamentos. Apesar disso, o azevém e o consórcio apresentaram um ciclo de pastejo a mais $(\mathrm{P}<0,01)$ que a aveia pura (Tab. 1). Os pastos consorciados e o azevém puro apresentaram maior taxa de acúmulo $(\mathrm{P}<0,01)$, contudo, devido ao maior período de utilização dos pastos consorciados, estes tiveram maior produção total de matéria seca $(\mathrm{P}<0,001)$ em comparação aos pastos cultivados puros (Tab. 1).
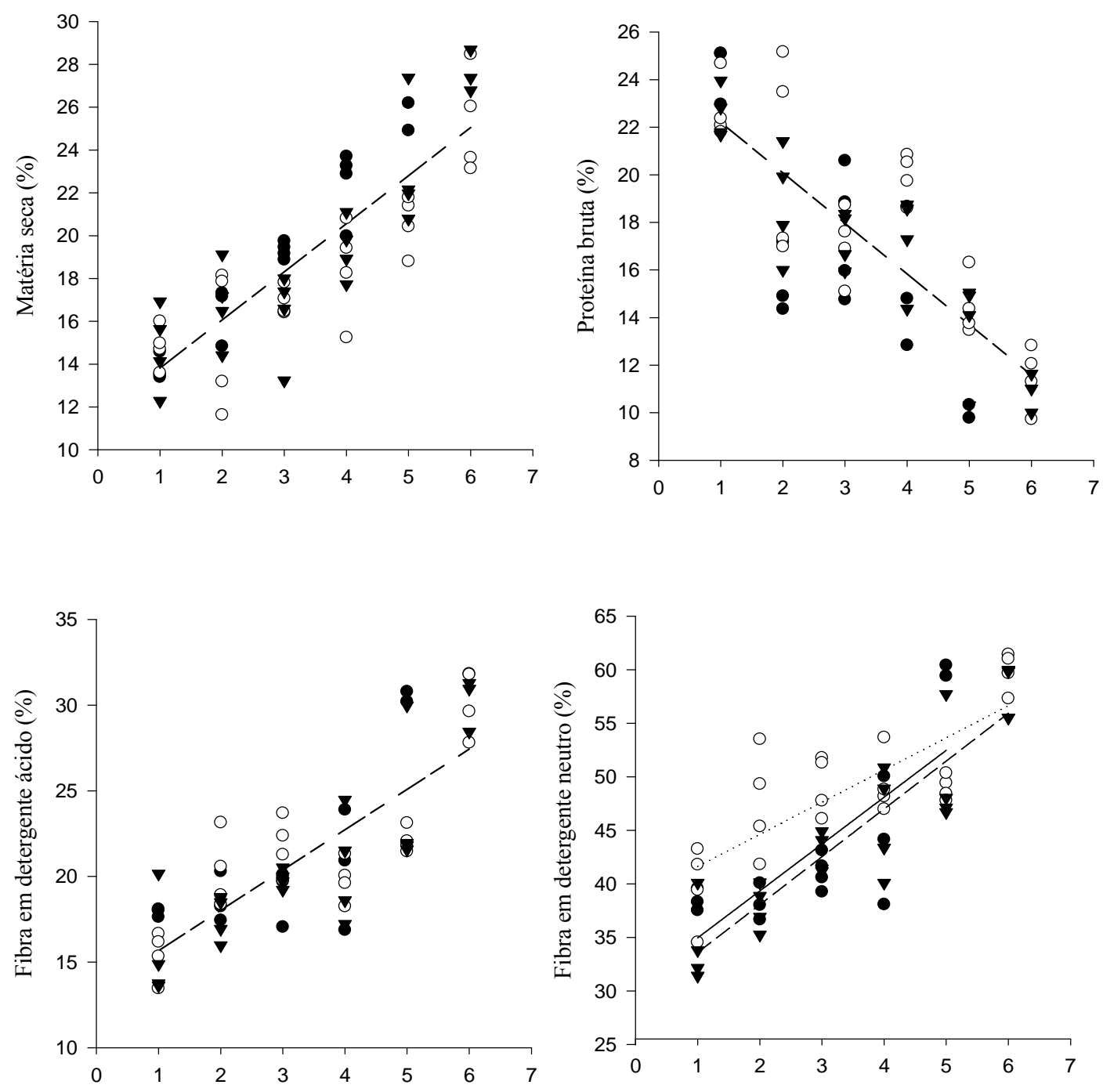

Ciclos de pastejo

Figura 2. Composição química de pastos de aveia $(\bullet)$, azevém $(\circ)$ e consórcio $(\boldsymbol{\nabla})$, ao longo da estação de crescimento. Matéria seca $\left(\%\right.$ verde): efeito linear $(\mathrm{P}<0,001) ;(\mathrm{y}=11,5+2,2 \mathrm{x}) \mathrm{R}^{2}=0,74$. Proteína bruta (\% MS): efeito linear $(\mathrm{P}<0,0001) ;(\mathrm{y}=24,3-2.15 \mathrm{x}) \mathrm{R}^{2}=0,64$. FDA $(\% \mathrm{MS})$ : efeito linear $(\mathrm{P}<0,0001) ;(\mathrm{y}=13,3+2,4 \mathrm{x}) \mathrm{R}^{2}=0,64$. FDN $(\% \mathrm{MS})$ : aveia $(\bullet-)$, efeito linear $\mathrm{P}<0,0001(\mathrm{y}=29+$ $4,9 x) R^{2}=0,57$; azevém $\left(\mathrm{o}^{\cdots \cdots}\right)$ efeito linear $\mathrm{P}<0,0001(\mathrm{y}=38,6+3 \mathrm{x}) \mathrm{R}^{2}=0,63$; e consórcio $\left(\boldsymbol{\nabla}-\mathrm{-}_{-}\right)$efeito linear $\mathrm{P}<0,0001(\mathrm{y}=29+4,5 \mathrm{x}) \mathrm{R}^{2}=0,82$. 


\section{Guzatti et al.}
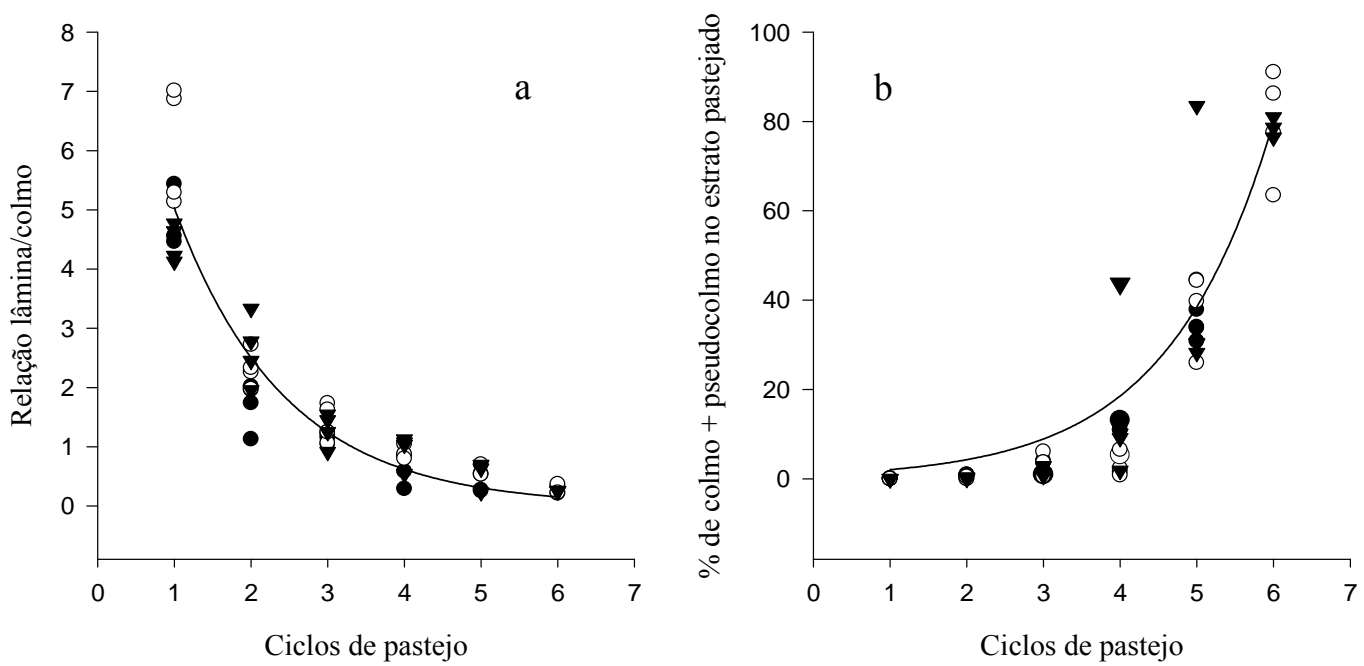

Figura 3. (a) Relação lâmina:colmo em pastos de aveia $(\bullet)$, azevém (o) cultivados puros e em consórcio ( $\boldsymbol{\nabla})$ ao longo da estação de crescimento. Efeito exponencial: $\mathrm{P}<0,0001 ; \mathrm{R}^{2}=0.91 ; \mathrm{y}=7,83 \mathrm{e}^{-0,571 \mathrm{x}}$. (b) Porcentagem de colmo + pseudocolmo no estrato pastejado em pastos de aveia $(\bullet)$, azevém (०) cultivados puros e em consórcio $(\boldsymbol{\nabla})$ ao longo da estação de crescimento. Efeito exponencial: $\mathrm{P}<0,0001 ; \mathrm{R}^{2}=0.86$; $y=9,73 \mathrm{e}^{-0,72 \mathrm{x}}$.

Tabela 1. Datas do primeiro e do último pastejo (dia/mês), número de ciclos, produção total ( $\left.\mathrm{kg} \mathrm{MS} \mathrm{ha}^{-1}\right)$ e taxa de acúmulo ( $\mathrm{kg} \mathrm{MS} \mathrm{ha}{ }^{-1}$ dia $^{-1}$ ) em pastos de aveia-preta (cv. IAPAR-61) e azevém anual (cv. Comum) cultivados puros ou em consórcio

\begin{tabular}{|c|c|c|c|c|}
\hline & Aveia & Azevém & Consórcio & $\mathrm{P}=$ \\
\hline $\begin{array}{l}1^{\mathrm{o}} \text { pastejo } \\
\text { (dia/mês) }\end{array}$ & $12 / 07$ & $13 / 07$ & $15 / 07$ & - \\
\hline $\begin{array}{l}\text { Último pastejo } \\
\text { (dia/mês) }\end{array}$ & $01 / 11$ & $18 / 10$ & $03 / 11$ & - \\
\hline $\mathrm{N}^{\mathrm{o}}$ de ciclos & $\begin{array}{c}5 b \\
(0,13)\end{array}$ & $\begin{array}{c}6 \mathrm{a} \\
(0,10)\end{array}$ & $\begin{array}{c}6 \mathrm{a} \\
(0,10)\end{array}$ & 0,0058 \\
\hline $\begin{array}{c}\text { Produção total } \\
\left(\mathrm{kg} \text { MS ha }{ }^{-1}\right)\end{array}$ & $\begin{array}{c}3891 \mathrm{c} \\
(63)\end{array}$ & $\begin{array}{l}4359 b \\
(51,4)\end{array}$ & $\begin{array}{l}4809 a \\
(51,4)\end{array}$ & 0,0003 \\
\hline $\begin{array}{l}\text { Taxa de acúmulo } \\
\left(\mathrm{kg} \mathrm{MS} \mathrm{ha}^{-1} \mathrm{dia}^{-1}\right)\end{array}$ & $\begin{array}{l}26,5 b \\
(0,68)\end{array}$ & $\begin{array}{l}32,8 \mathrm{a} \\
(0,56)\end{array}$ & $\begin{array}{l}32,3 \mathrm{a} \\
(0,56)\end{array}$ & 0,0016 \\
\hline
\end{tabular}

Médias seguidas pela mesma letra na linha não diferem entre si.

Os números entre parênteses correspondem ao erro padrão da média.

\section{DISCUSSÃO}

Embora elevações nos teores de FDN e FDA no final da estação de desenvolvimento das plantas fossem esperadas, devido ao acúmulo de carboidratos estruturais na parede celular das forrageiras (Gerdes et al., 2005), o pastejo leniente manteve a qualidade da forragem no estrato pastejado em níveis não prejudiciais à produção animal durante o estádio vegetativo de desenvolvimento dos pastos. $\mathrm{O}$ aumento linear nos teores de fibra e a redução no teor de proteína não foram suficientes para que a forragem no estrato pastejado apresentasse 
valores de FDN superiores a $50 \%$ e de PB inferiores a $16 \%$ nos quatro primeiros ciclos de pastejo (estádio vegetativo) para todos os tratamentos. Nessa situação, a forragem produzida é de excelente qualidade, e, portanto, produções de leite acima de $20 \mathrm{~kg} /$ dia e ganhos médios diários acima de $1 \mathrm{~kg} /$ dia são possíveis de serem obtidos sem a utilização de alimentos concentrados (INRA, 2007). De outra forma, a maior participação de colmos + pseudocolmos no estrato pastejado a partir do quarto ciclo de pastejo esteve associada a valores de FDN acima de $55 \%$ e de PB abaixo de $12 \%$, consequência direta do início do estádio de desenvolvimento reprodutivo desses pastos. Isso provavelmente ocorreu porque os tecidos de sustentação desenvolvidos nesse momento apresentam teores mais elevados de fibra e mais baixos de proteínas e carboidratos não estruturais quando comparados às laminas foliares (Nelson e Moser, 1994).

Durante toda a estação de crescimento dos pastos, as alturas em pré e pós-pastejo ficaram dentro das metas estabelecidas, com exceção do azevém puro nos dois últimos ciclos de pastejo (alturas de 2 e $3 \mathrm{~cm}$ acima da meta pré-pastejo e de 1 e $2 \mathrm{~cm}$ acima da meta pós-pastejo no quinto e sexto ciclos, respectivamente). $\mathrm{O}$ aumento na altura pré- pastejo ocorreu pelo rápido alongamento de colmos, devido ao início do estádio reprodutivo dessa espécie, o qual aumentou drasticamente a quantidade de colmo + pseudocolmo na forragem a ser colhida. Esse comportamento reduziu a qualidade da forragem (Leonel et al., 2009) e, assim, aumentou a resistência à colheita e dificultou o rebaixamento dos pastos pelos bovinos (Benvenutti et al., 2009), justificando as alturas em pós-pastejo acima da meta. Esses resultados mostram a importância de se adotarem estratégias que retardem ao máximo a entrada das plantas em estádio reprodutivo. Nesse sentido, o controle da altura pré-pastejo associado a estratégias que estimulem o perfilhamento, como a adubação nitrogenada (Caminha et al., 2010) e maiores severidades de desfolhação nos primeiros ciclos de pastejo (Lara e Pedreira, 2011), pode ser de grande valia. Assim, a utilização da biomassa como critério para realizar o primeiro pastejo em gramíneas anuais pode demandar tempo e permitir elevado crescimento de material para sustentação. Isso irá refletir em aumento da proporção de colmos no estrato pastejável, redução da qualidade da forragem ingerida e antecipação de entrada das plantas em estádio reprodutivo, demonstrando que a quantidade de biomassa aérea não é o melhor critério para tomada de decisão quanto à entrada dos animais nos piquetes.

A produção total de MS e a taxa de acúmulo no consórcio demonstram que não houve qualquer tipo de prejuízo decorrente de competição interespecífica que pudesse diminuir a produção de biomassa em comparação aos cultivos puros. Isto provavelmente ocorreu porque o consórcio entre aveia e azevém é capaz de manter um índice de área foliar constante por meio de ajustes na população de perfilhos de cada espécie ao longo do período de utilização (Duchini et al., 2014). Além disso, segundo Aarssen (1985), espécies que apresentam similaridades morfogênicas aproximam os efeitos das competições intra e interespecíficas, de modo a permitir sua coexistência, provavelmente sem prejuízos em seus processos de desenvolvimento e crescimento. Em contrapartida, a menor taxa de acúmulo observada para a aveia pode ser parcialmente atribuída à ocorrência de baixas temperaturas observadas ao longo do experimento, uma vez que essa espécie apresenta temperatura basal superior à do azevém anual (Duru e Ducrocq, 2000; Santos et al., 2009). Além disso, cabe ressaltar que as produções de biomassa aérea observadas neste trabalho foram semelhantes ao observado por outros autores tanto para a aveia pura (Moreira et al., 2001) como para o consórcio (Macari et al., 2006). Finalmente, as baixas temperaturas médias no início do experimento, associadas ao menor potencial de perfilhamento (Langer, 1972) e ao cultivar utilizado (ciclo longo e tardio), podem ser apontadas como as principais causas de o primeiro pastejo da aveia ter acontecido praticamente na mesma data que o azevém puro e o consórcio e por permitir seu pastejo até o início de novembro. Da mesma forma, as baixas temperaturas e a altura de manejo em pré-pastejo (superior aos demais tratamentos) podem ter contribuído para que a aveia pura apresentasse um ciclo de pastejo a menos. O final do período experimental se deu pela elevada emissão de inflorescências a partir do quinto ciclo de pastejo, principalmente do azevém em ambas as formas de cultivo, bem como pela necessidade de preparo da área para o plantio de culturas de verão. 


\section{CONCLUSÃO}

O uso do pastejo leniente ao longo do período de utilização de pastos anuais de inverno mantém a qualidade químico-bromatológica da forragem no estrato pastejado durante todo o estádio de desenvolvimento vegetativo. A associação entre aveia-preta e azevém anual aumenta a produção de matéria seca total de forragem em comparação aos mesmos pastos cultivados puros.

\section{REFERÊNCIAS}

AARSSEN, L.W. Interpretation of the evolutionary consequences of competition in plants: An experimental approach. Oikos, v.45, p.99-109, 1985.

ALLAN, E.; WEISSER, W.; WEIGELT, A. et al. More diverse plant communities have higher functioning over time due to turnover in complementary dominant species. Proc. Nat. Acad. Sci., v.108, p.17034-17039, 2011.

BENVENUTTI, M.; GORDON, I.J.; POPPI D.P. et al. The horizontal barrier effect of stems on the foraging behaviour of cattle grazing five tropical grasses. Liv. Sci., v.126, p.229-238, 2009.

CAMINHA, F.O.; SILVA, S.C.; PAIVA, A.J. et al. Estabilidade da população de perfilhos de capim-marandu sob lotação contínua e adubação nitrogenada. Pesqui. Agropecu. Bras., v.45, p.213-220, 2010.

CARRÈRE, P.; PONTES, L.; FABRE, P. et al. The interspecific plant competition affects the production and the nutritive value of grassland species. In:. GENERAL MEETING ON SUSTAINABLE GRASSLAND PRODUCTIVITY, 21., 2006, Badajoz, Spain. Proceedings... Baajoz: European Grassland Federation, 2006.

CARVALHO, P.C.F.; ROCHA, L.M.; BAGGIO, C. et al. Característica produtiva e estrutural de pastos mistos de aveia e azevém manejados em quatro alturas sob lotação contínua. Rev. Bras. Zootec., v.39, p.1857-1865, 2010.

DIAGNÓSTICO de sistemas de produção da bovinocultura de corte do Estado do Rio Grande do Sul. Porto Alegre: UFRGS/IEPE, 2005. 265p. (Relatório de Pesquisa).
DUCHINI, P.G.; GUZATTI, G.C.; RIBEIROFILHO, H.M.N.; SBRISSIA, A.F. Tiller size/density compensation in temperate climate grasses grown in monoculture or in intercropping systems under intermittent grazing. Grass. Forage Sci., v.69, p.655-665, 2014.

DURU, M.; DUCROCQ, H. Growth and senescence of the successive grass leaves on a tiller. Ontogenic development and effect of temperature. Ann. Bot., v.85, p.635-643, 2000.

FONSECA, L., MEZZALIRA, J.C., BREMM, C. et al. Management targets for maximising the short-term herbage intake rate of cattle grazing in Sorghum bicolor. Liv. Sci., v.145, p.205-211, 2012.

GERDES, L.; MATTOS, H.B.; WERNER, J.C. et al. Composição química e digestibilidade da massa de forragem em pastagem irrigada de capim-Aruana exclusivo ou sobre-semeado com mistura de aveia preta e azevém. Rev. Bras. Zootec., v.34, p.1098-1108, 2005.

HARRIS, W.; THOMAS, V. J. Competition among pasture plants. New Zeal. J. Agr. Res., v.15, p.19-32, 1972.

HELLBRUGGE, C.; MOREIRA, F.B.; MIZUBUTI, I.Y. et al. Desempenho de bovinos de corte em pastagem de azevém (Lolium multiflorum) com ou sem suplementação energética. Semina: Ciênc. Agr., v.9, p.723-730, 2008.

HERNANDEZ-GARAY, A.; MATTHEW, C.; HODGSON J. Tiller size/density compensation in perennial ryegrass miniature swards subject to differing defoliation heights and a proposed productivity index. Grass. Forage Sci, v.54, p.347-356, 1999.

INRA (Ed.). Alimentation des bovins, ovins et caprins. Quae, Paris: INRA, 2007. 330p.

LANGER, R. H. M. How grasses grow. London, Edward Arnold, 1972. 60p. (Studies in Biology, 34).

LARA, M.A.S; PEDREIRA, C.G.S. Respostas morfogênicas e estruturais de dosséis de espécies de Braquiária à intensidade de desfolhação. Pesqui. Agropecu. Bras., v.46, p.760-767, 2011. 
LEONEL, F.P.; PEREIRA, J.C.; COSTA, M.G. et al. Comportamento produtivo e características nutricionais do capim-braquiária cultivado em consórcio com milho. Rev. Bras. Zootec., v.38, p.177-189, 2009.

MACARI, S.; ROCHA, M.G.; RESTLE, J. et al. Avaliação da mistura de cultivares de aveia preta (Avena strigosa Schreb) com azevém (Lolium multiflorum Lam.) sob pastejo. Cienc. Rural, v.36, p.910-915, 2006.

MANUAL de adubação e calagem para os Estados de Rio Grande do Sul e Santa Catarina. 10 ed. Porto Alegre: COMISSÃO DE QUÍMICA E FERTILIDADE DO SOLO, 2004. 400p.

MIGUEL, M.F.; RIBEIRO-FLHO, H.M.N.; CRESTANI, S. et al. Pasture characteristics of Italian ryegrass and milk production under different management strategies. Pesqui. Agropecu. Bras., v.47, p. 863-868, 2012.

MOREIRA, F.B.; CECATO, U.; PRADO, I.N. et al. Avaliação de aveia preta $c V$ Iapar 61 submetida a níveis crescentes de nitrogênio em área proveniente de cultura de soja. Acta Sci., v.23, p. $815-821,2001$.

MOREIRA, F.B.; PRADO, I.N.; SOUZA, N.E. et al. Desempenho animal e características da carcaça de novilhos terminados em pastagem de aveia preta, com ou sem suplementação energética. Acta Sci. Anim. Sci, v.27, p.469-473, 2005.
NELSON, C.J., MOSER, L.E. Plant factors affecting forage quality. In: FAHEY JR., G.C. (Ed.). Forage quality, evaluation and utilization. Madison: American Society of Agronomy. 1994. p.115-154.

SANTOS, G.T.; ZANINI, G.D.; PADILHA, D.A; SBRISSIA, A.F. A grazing height target to minimize tiller stem elongation rate in annual ryegrass swards. Cienc. Rural. No prelo.

SANTOS, H.P.; FONTANELI. R.S.; FONTANELI, R.S.; OLIVEIRA, J.T. Gramíneas anuais de inverno. In: FONTANELI, R.S. et al. (Eds.). Forrageiras para integração lavourapecuária-floresta na região sul-brasileira. Passo Fundo: Embrapa Trigo, 2009. 340p.

SISTEMA brasileiro de classificação de solos. 2.ed. Rio de Janeiro: Embrapa Solos, 2006. 306p.

SOARES, A.B.; CARVALHO, P.C.F.; NABINGER, C. et al. Produção animal e de forragem em pastagem nativa submetida a distintas ofertas de forragem. Cienc. Rural, v.35, p.1148-1154, 2005.

SPEHN, E.M.; JOSHI, J.; SCHMID, B. et al. Above-ground resource use increases with plant species richness in experimental grassland ecosystems. Funct. Ecol., v.14, p.326-337, 2000.

VAN SOEST, P.J.; ROBERTSON, J.B.; LEWIS, B.A. Methods for dietary fiber, neutral detergent fiber, and nonstarch polysaccharides in relation to animal nutrition J. Dairy Sci., v.74, p.3583 3597, 1991. 